\title{
Associated Liver Disease in Alcoholic Chronic Pancreatitis
}

\author{
S.P Girish ${ }^{\circledR}$, Jagan Mohan B Reddy ${ }^{\circledR 2}$ \\ ${ }^{1}$ Associate Professor, Department of Surgical Gastroenterology, Sapthagiri Institute of Medical Sciences and Research Centre, Bangalore, Karnataka, India, ${ }^{2}$ Assistant \\ Professor, Department of Surgical Gastroenterology, Sapthagiri Institute of Medical Sciences and Research Centre, Bangalore, Karnataka, India.
}

\section{Abstract}

Background: Alcohol is a common etiological factor in the pathogenesis of both pancreatic and liver disease. The frequencies of associated liver histological change in patients with alcoholic chronic pancreatitis (AICP) vary from series to series. Significant proportion of patients with alcoholic pancreatitis does have histological changes in liver. Subjects and Methods: The study was conducted at Narayana Medical College \& Hospital, Chintareddy Palem, Nellore, Andhra Pradesh on liver-biopsy specimens from 23 patients with chronic alcoholic pancreatitis subjected to operation for pain, from August 2015 to July 2016 and all the patients had undergone liver biopsy at the time of surgery for AICP. The patients were followed as part of a prospective study of 33 patients who had been treated for chronic pancreatitis. The pathologists were requested to report on alcohol related histological changes in the specimen. Results: There were 23 patients and all were men. Chronic pancreatitis was due to alcohol abuse in all patients. The median age at surgery was 39.8 years. The mean duration of alcohol abuse was 20.5 years (range 6-29 years). The average alcohol intake was $122 \mathrm{gm} \pm 36 \mathrm{gms} /$ day. Three patients had jaundice for 3-6 months duration. None of the patients had any other risk factor for liver disease and none of them had clinical or biochemical evidence of liver disease. The histological reports were, 4 patients had alcoholic hepatitis, 2 severe steatohepatitis, 1 granulomatous hepatitis, 3 cholestasitc changes, one fatty liver and 12 had no significant pathology. None of the patients had cirrhosis. Thus significant alcoholic liver disease was present in $30.4 \%$ (7/23) of the patients. There was no increased incidence of post-operative mortality and morbidity in patients with liver pathology. Conclusion: As reported in many other series, chronic alcoholic pancreatitis is associated with histological changes in liver in significant proportion of patients. However its clinical significance and prognosis of these patients are unknown.

Keywords: Pancreas, Alcohol, Pancreatitis

Corresponding Author: Jagan Mohan B Reddy, Assistant Professor, Department of Surgical Gastroenterology, Sapthagiri Institute of Medical Sciences and Research Centre, Bangalore, Karnataka, India.

E-mail: sweetjagan20204u@gmail.com

Received: 15 March 2020

Revised: 29 May 2020

Accepted: 14 June 2020

Published: 5 July 2020

\section{Introduction}

Alcohol abuse is a common etiological factor in the pathogenesis of both liver and pancreatic disease. The disease coexistence has been variable according to the literature. There is considerable controversy in the incidence of association of liver disease with alcoholic pancreatitis. Most of the studies are conducted very long back in 1970s.Afterwards there is paucity in the investigation regarding this issue. It is still not clear whether this association of liver disease in AICP is significant and does it affect the prognosis of patients with AICP. Clark et al reported $47 \%$ of cirrhosis in an autopsy series of 36 patients of AICP. Howard and Jordan demonstrated $40 \%$ incidence of cirrhosis in a retrospective study of 94 patients. In a recent series, Gullo $\mathrm{L}$ et al reported $44 \%$ associated abnormal liver histology in AICP. However, Sarles et al reported only 1 case of cirrhosis in 100 cases of chronic pancreatitis. Further,
Marks et al found only 7 Cases of cirrhosis in review of 148 cases of AICP. Hence the reports are variable regarding the incidence of association of ALD with AICP.

Our clinical observation did indicate significant association of liver disease in AICP in contrast to literature. Therefore we decided to investigate this experience prospectively.

\section{Subjects and Methods}

The study was conducted at Narayana Medical College \& Hospital, Chintareddy Palem, Nellore, Andhra Pradesh on liver-biopsy specimens from 23 patients with chronic alcoholic pancreatitis subjected to operation for pain, from August 2015 to July 2016 and all the patients had undergone liver biopsy at the time of surgery for AICP. The diagnosis of chronic alcoholic pancreatitis was based on history of alcoholism for several years, clinical symptoms and investigations results. 
Radiologic investigations confirmed the diagnosis of $\mathrm{CP}$ in all patients with presence of ductal calcification, dilatation and presence of peudocyst. Associated complication such as biliary obstruction was specially considered as it may cause additional histological changes in liver. Patients with a history of, or the demonstrated presence of peptic ulcer disease, gall bladder disease, biliary tract disease, or recent abdominal surgery or trauma were excluded. In addition, patients with primary hyperlipidemia, hypercalcemia, or steroid therapy were also excluded. Apart from this, the presence or absence of liver disease, based on clinical, biochemical and radiological parameters was taken into account. Each patient selected was interviewed to determine specially the daily ethanol consumption, the percent of total daily calories that were ethanol and the duration of drinking. Additional informed consent was taken from all patients undergoing surgery for liver biopsy.

Liver true cut biopsies from both lobes were obtained during laparotomy in all patients. The liver biopsy specimen was examined by the pathologist without knowledge of surgical and clinical data. Liver histopathological appearance was evaluated for a) liver architecture, in particular the presence, intensity and location of fibrosis and b) associated lesions suggesting alcoholic liver disease (steatosis, alcoholic hepatitis). Over all incidence of liver disease was noted and results were analyzed based on two groups of patients with or without alcoholic liver disease.

\section{Results}

All patients were male; the mean age was $39.8 \pm 10.2$ years. All were suffering from intractable pain not adequately to NSAIDs. Duration of alcohol intake was ranging from 6 to 29 years (Median -20.3 years).Five patients (21\%) had pancreatic pseudocyts; all were demonstrated by either radiological or ultrasound study. Pancreatic insufficiency was present in 2 $(0.8 \%)$, and $19(82 \%)$ had pancreatic calcification. None of the patients had clinical liver disease. Histologically significant liver disease was seen in 11 of the 23 liver biopsies; The histological reports were, 4 patients had alcoholic hepatitis, 2 severe steatohepatitis, 1 granulomatous hepatitis, 3 cholestasitc changes, one fatty liver and 12 had no significant pathology. [Table 1] summarizes the alcohol intake for the groups as a whole and for those with and those without liver disease. There were no differences by historical interview between the duration of the drinking, the daily alcohol consumption, or the fraction of total calories taken as alcohol. Further, the duration or the amount of ethanol abuse did not correlate with the presence of the liver disease in chronic pancreatitis group. The mean duration of pancreatitis was found to be $2.6 \pm 1.7$ years in 23 patients with chronic pancreatitis where the information was available and did not correlate with biopsy proven significant liver disease.

\section{Post-operative morbidity and mortality.}

Post-operative complication included wound infection, pancreatic leak, chest infection and GI bleed. Over all complication occurred in 7 patients. There was no mortality in the study group. Over all morbidity with subgroup division is given in the [Table 2]. There was increase in the rate of complications in liver disease group which was statistically significant. The duration of hospital stay also varied between these two groups. Total hospital stay was 6.96 days. However it was 5.81 days in without liver disease verses 9.57 days in liver disease group. These increased complication rates may be related to liver disease because incidence of other comorbid factors were evenly distributed in both the groups.

\section{Discussion}

The frequency of associated liver disease in alcoholic pancreatitis has been reported to be variable. ${ }^{[1-3]}$ While transiently abnormal liver function tests are seen in a large number of patients with alcohol pancreatitis, histological defined liver disease, particularly alcoholic cirrhosis, is considered rare. ${ }^{[4]}$ In our study histologically diagnosed liver disease is seen in approximately $30 \%$ of cases with chronic alcoholic pancreatitis. The nature of associated liver disease in this study was mostly either inflammatory (i.e. alcoholic hepatitis in 57.1\%) and/or severe fatty changes. Several studies have indicated that alcohol can induce a wide variety of clinical and histopathological liver diseases in humans and animals. Moreover, fibrosis associated with chronic pancreatitis may result in significant narrowing of the distal common bile duct which may present clinically as extra hepatic obstructive jaundice or contribute to a secondary biliary cirrhosis. ${ }^{[5]}$

It has been proposed that the alcoholic with chronic pancreatitis consumes larger amounts of alcohol as compared to the patients with acute pancreatitis. The daily consumption of alcohol for the whole group (122 g/day) in the present series was significantly different from that reported by Sarles (179 g.day) and Gullo L. ${ }^{[2,6]}$ In a study by Dutta SK D et al, ${ }^{[1]}$ which had shown high incidence of liver disease has $168 \mathrm{gm}$ alcohol intake per day. This difference in average intake of alcohol is different in individual society. Dividing our patients into those with and those without liver disease, there were almost identical intakes of alcohol in the two groups. Lelbach has shown a very good correlation by epidemiologic studies between the total amount and duration of alcohol consumed, ${ }^{[7]}$ and the frequency of alcoholic cirrhosis. Lelbach's data clearly indicate that when alcohol consumption of more than one pint/day was continued for 12 years, about $25 \%$ of alcoholic developed cirrhosis. In our series the amount of alcohol consumed was $122 \pm 36 \mathrm{~g} /$ day for a mean duration of 20 years. However, there was no difference in the amount and duration of alcohol consumption between the group which developed liver disease vs 
Table 1: Amount and duration of alcohol consumption in all patients with alcoholic pancreatitis

\begin{tabular}{llll} 
& Whole group $(\mathbf{n}=\mathbf{2 3})$ & $\begin{array}{l}\text { A, alcoholic pancreatitis } \\
\text { without liver disease }\end{array}$ & $\begin{array}{l}\text { Blcoholic pancreatitis } \\
\text { with liver disease }\end{array}$ \\
$\begin{array}{l}\text { Mean daily alcohol consump- } \\
\text { tion (g/day }\end{array}$ & $122 \pm 36$ & $120 \pm 25$ & $126 \pm 38$ \\
$\begin{array}{l}\text { Duration of alcohol abuse } \\
\text { (years) }\end{array}$ & 20.48 & 20.94 & 19.17 \\
\hline
\end{tabular}

\begin{tabular}{llll}
\hline Table 2: Complications & & & \\
\hline Complications & Whole group N=23 & Without liver disease $\mathbf{N = 1 6}$ & With liver disease N=7 \\
\hline Wound infection & $6(26 \%)$ & $2(12.3 \%)$ & $4(57 \%)$ \\
Chest infection & $1(4 \%)$ & 0 & $1(14 \%)$ \\
\hline $\begin{array}{l}\text { Pancreatic fistula } \\
\text { GI bleed, self }\end{array}$ & $1(4 \%)$ & 0 & $1(14 \%)$ \\
ing(errosive) & $1(4 \%)$ & 0 & $1(14 \%)$ \\
\hline
\end{tabular}

the group which did not.

The mean age of patients in our series was $39.8 \pm 10.2$ years while it was $38.4 \pm 18$ years in Sarles series of chronic calcifying pancreatitis. The mean age of patients in Clark's and Howard's series with high frequency of liver disease was43 and 33 years respectively. ${ }^{[3,8]}$ In patients with liver disease, the duration of alcohol consumption (mean 19.7 years, range 10-28 years) was similar in patients without ALD (mean 20.4 years, range 6-29 years). In contrast in a study by Gullo L et al, ${ }^{[2]}$ patients with cirrhosis, the duration of alcohol consumption (mean 27.6 years, range 18-42 years) was significantly longer $(\mathrm{p}<0.05)$ than in patients without ALD (mean 19.7 years, range 8-36years).

In most of the earlier series the clinical or histological evidence of cirrhosis was very common ranging from $10-33 \%$. The fact that AICP occurs earlier than liver cirrhosis and the fact that many patients stop alcohol consumption after the first attacks of pancreatic pain may explain, at least in part, the apparent rarity with which this association has been indicated by previous studies. In our study liver disease was subclinical in all patients and none of the patients had severe fibrosis or cirrhosis.

The clinical impact of this observation is not studied in the literature. Our effort to analyze this aspect yielded some significant results. Patients with significant liver disease are prone to more post-operative complications than the counterpart. The draw back our study is small number of patients in the study group. Other problem in prognostication is that, the subclinical nature of the disease that cannot be predicted by routine clinical parameters.

\section{Conclusion}

The association of ALD with AICP is much more common than previously believed. Thus a substantial number of patients with alcoholic pancreatitis appear to have significant associated liver disease. This association is meaningful in more effective management of these patients in general and in preoperative assessment of the risk of surgery in particular.

\section{References}

1. Dutta SK, Mobrahan S, Iber FL. Associated liver disease in alcoholic pancreatitis. Am J Dig Dis. 1978;23(7):618-622. Available from: https://dx.doi.org/10.1007/bf01072596.

2. Gullo L, Casadei R, Campione O, Grigioni W, Marrano D. Alcoholic liver disease in alcoholic chronic pancreatitis: a prospective study. Ital J Gastroenterol. 1995;27(2):69-72.

3. Perumpai BJ, Khan MA, Yoo ER, Cholankeril G, Kim D, Ahmed A. Clinical epidemiology and disease burden of nonalcoholic fatty liver disease. World J Gastroenterol. 2017;23(47):82638276. Available from: https://dx.doi.org/10.3748/wjg.v23.i47. 8263.

4. Renner IG, Savage WT, Stace NH, Pantoja JL, Schultheis WM, Peters RL. Pancreatitis associated with alcoholic liver disease. Dig Dis Scienc. 1984;29(7):593-599. Available from: https: //dx.doi.org/10.1007/bf01347290.

5. Angelini G, Merigo F, Degani G, Camplani N, Bovo P, Pasini F, et al. Association of chronic alcoholic liver and pancreatic disease: a prospective study. Am J Gastroenterol. 1985;80(12):998-1003.

6. Sarles H, Sarles JC, Camatte R, Muratore R, Gaini M, Guien $\mathrm{C}$, et al. Observations on 205 confirmed cases of acute pancreatitis, recurring pancreatitis, and chronic pancreatitis. Gut. 1965;6(6):545-559. Available from: https://dx.doi.org/10.1136/ gut.6.6.545.

7. Lelbach WK. Epidemiology of alcoholic liver disease. Prog Liver Dis. 1976;5:494-515. 
8. Perumpail BJ, Khan MA, Yoo ER, Cholankeril G, Kim D, Ahmed A. Clinical epidemiology and disease burden of nonalcoholic fatty liver disease. World J Gastroenterol. 2017;23(47):8263-8276. Available from: https://dx.doi.org/10. 3748/wjg.v23.i47.8263.

Copyright: (C) the author(s), 2020. It is an open-access article distributed under the terms of the Creative Commons Attribution License (CC BY 4.0), which permits authors to retain ownership of the copyright for their content, and allow anyone to download, reuse, reprint, modify, distribute and/or copy the content as long as the original authors and source are cited.

How to cite this article: Girish SP, Reddy JMB. Associated Liver Disease in Alcoholic Chronic Pancreatitis. Acad. J Surg. 2020; 3(1):172-175

DOI: dx.doi.org/10.47008/ajs/2020.3.1.37

Source of Support: Nil, Conflict of Interest: None declared. 